\title{
From Positive Psychology to Positive Development: Overcoming Adversity and Flourishing in Emerging Adulthood
}

\author{
Joseph Lah Lo-oh \\ Faculty of Education, The University of Bamenda, P.O. Box 39, Bambili, Bamenda, NW Region, Cameroon
}

\begin{abstract}
During the past half-century, the transition to adulthood has become increasingly prolonged in virtually all parts of the world. Young people today stay in school longer, marry later, and have their first child later than they did in the past. Besides, media portrayals of them often seem to emphasize the problems that can be a part of young people. Gang violence, school shootings, alcohol-related accidents, drug abuse, and suicides involving teens are all too frequently reflected in newspaper headlines and movie plots. In the professional literature, too, adolescence is frequently portrayed as a negative stage of life - a period of storm and stress as well as turmoil and trouble to be survived or endured through the period. But with the attention given to negative images of adolescents and youth, however, the positive aspects of their development can be overlooked. As a result, emerging adults are increasingly required to "individualize" their life courses in general and their identities in particular, by taking the initiative to form working and personal relationships, to gain educational credentials and employment experience, and to plan for the future. Those who address these issues in a proactive, resilient and agentic manner may be most likely to form a coherent sense of identity that can be used to guide their life paths and to negotiate for social resources and positions. This article therefore benefits from knowledge of positive psychology to inform positive and productive development for young people in troubled circumstances. While we dig into some of the deprived developmental circumstances in which African emerging adults in particular develop, we also pay attention to how they benefit from positive psychology in order to navigate positive life courses for themselves.
\end{abstract}

Keywords: Positive psychology, Positive development, Adversity, Flourishing, Emerging adulthood.

DOI: $10.7176 / \mathrm{JCSD} / 46-06$

Publication date:March $31^{\text {st }} 2019$

\section{Introduction}

During the past half-century, the transition to adulthood has become increasingly prolonged in virtually all parts of the world. Young people all over today stay in school longer, marry much later, and have their first child later than their parents did in the past (e.g., Arnett, 2004; White, 2003; Lo-oh, 2012). Because the transition to adulthood can last from the late teens until at least the mid-20s in industrialized societies and up to the $30 \mathrm{~s}$ in developing countries, it has been proposed that these years now constitute a potentially new and distinct developmental period, called emerging adulthood, between adolescence and full adulthood. The use of this term is becoming increasingly widespread (e.g., Arnett, 2000; Hagan \& Foster, 2003), and efforts are underway to better understand the developmental antecedents and consequences of the new age. By so doing the period is gradually becoming a unique developmental stage in the human life course.

The transition to adulthood has become increasingly prolonged as a result of economic changes, and many aspects of the life course have also become increasingly preference-based than society-based as a result of cultural and social changes (Wallace \& Kovatcheva, 1998). In most parts of the world, market-oriented policies and consumption-based lifestyles are replacing community-oriented policies and production-based lifestyles (Furlong \& Cartmel, 1997). Consequently, life-course events that were once more normatively structured (e.g., school completion, finding a job, exit from the parental home, marriage, gender roles and so on) are increasingly left to individuals to decide on their own, leaving them to take on new responsibilities for living with the consequences of their actions and decisions (Bauman, 2001).

In addition to the challenges emanating from these changes, media portrayals of these young people also often seem to emphasize the problems that can be a part of adolescence and the transition to adulthood. Gang violence, school shootings, alcohol-related accidents, drug abuse, and suicides involving young people are all too frequently reflected in newspaper headlines and movie plots, not only in industrialized societies but also too often in the developing world today. In the professional literature, too, adolescence is frequently portrayed as a negative stage of life - a period of storm and stress as well as turmoil and trouble to be survived or endured throughout the period (e.g. Arnett, 1999; Dusek, 1991). For some, it is a period that may span right up to the fourth decade of life, with the example of sub-Sahara Africa. With these, it may not be surprising that a 1999 survey of the general public by Public Agenda reported that for $71 \%$ of those polled, negative terms, such as "rude," "wild," and "irresponsible," first came to mind when respondents were asked what they thought about American teenagers (Public Agenda, 1999). At the same time, however, the survey found that $89 \%$ of the respondents believed that almost all teenagers could get back on track with the right kind of guidance and 
attention. These negative portrayals are somewhat even more domineering in developing countries, especially those hard-hit by social, economic and developmental handicapping conditions. A case in point would be young people in many African countries who are typically deprived by diverse and disturbing developmental circumstances. For example, African youth are hard hit by high unemployment rates leading to high levels of poverty, economic dependency and fewer opportunities towards leading productive lives (Lo-oh, 2014). While high school dropout rates and low transition to secondary school exist, labour market opportunities are extremely difficult to come by. And the World Bank (2014) reports that $72 \%$ of the youth population in Africa lives on less that $\$ 2$ a day. Health hazards are also rife with the HIV/AIDS pandemic and malaria ranking high among the youth. Despite these negative portrayals that sometimes seem so prevalent, however, the picture of young people today is largely a very positive one. Most of these deprived young people, especially in Africa, in fact, succeed in school, are attached to their families and their communities, and emerge from their teenage years without experiencing serious problems such as substance abuse or involvement in crime and violence.

In this connection, emerging adults are increasingly required to "individualize" their life courses in general and their identities in particular, by taking the initiative to form working and personal relationships, to gain educational credentials and employment experience, and to plan for their futures (Lo-oh, 2017). Those who address these deprivations in a proactive and agentic manner are most likely to form a coherent sense of identity that can then be used to guide their life paths and to negotiate for social resources, positions and dependable life courses. At the turn of the $21^{\text {st }}$ century, Martin Seligman, former head of the American Psychological Association, recognized an imbalance in psychological research around the world where psychological science had given too much attention to the negative side of personal psychology and too little attention to the positive, healthy side (Luthans, 2002). In light of this, Seligman (2009) called for research in what came to be known as "positive psychology." This article therefore benefits from knowledge of positive psychology to contribute to the positive and productive development of young people in troubled circumstances. While we dig into some of the deprived developmental circumstances African emerging adults in particular develop, we pay significant attention to how they benefit from positive psychology in order to navigate positive life courses for themselves.

\section{African troubled circumstances for youth development}

Africa's young people are immersed in a triple inheritance of Arabic-Islamic cultural fragments and WesternChristian legacies that have been superimposed on a highly resilient but ruthlessly haggled indigenous Africanity (Lo-oh, 2009; Nsamenang, 2005; Mazrui, 1986) far away from and off from African traditional religions. The African worldview conceives of the youth as growing out of childhood and poised for an adulthood that lies in the future (Araria, 2007; Nsamenang, 2002); and inextricably promising. And in African social ontogeny, adolescence is regarded as a "way station" between the stages of social apprenticeship in childhood and full social integration in adulthood beginning with social entré, a brief transitional period that marks the beginning of adult life (Nsamenang, 2002; Serpell, 1994). African young people are in fact, considered the bridge to Africa's future and the next generation and hope of the continent; and as such largely perceived in positive and productive ways. Transitions before and during emerging adulthood are typically characterized by rituals, rites of passage, and initiations into diverse sacred societies (Tchombe \& Lo-oh, 2012; Shumba \& Seeco, 2007). These cultural practices are positively cultured and thought to accompany the developing individual in positive ways, ensuring positive development. This suggests that from start, African children and youth are perceived positively and positive life measures are taken to shape their lives and destinies.

The transition period is also a time when young people are taken away to learn the ways of adults, returning with the skills necessary to fulfill that role in their particular community. For example, there is goat sacrifice and corn flour sacrifice for deceased maternal aunt or uncle and for deceased father among the Kom people of Cameroon to mark entry into adulthood (Tchombe \& Lo-oh, 2012); bogwera (for boys) and bojale (for girls) among the Setswana of Botswana (Shumba \& Seeco, 2007); and among the Nara ethnic group of Eritrea, there is a ceremony to celebrate manhood and womanhood during the period (Araria, 2007). Young people enter these rites as children, sometimes seen as "unclean," "not fit" (thus negatively) and emerge from them as not just adults, but acceptable and promising members of their family and community. However, in most African cultures, how young people negotiate and navigate their twenties and early thirties to eventually lead productive and functional adult lives is apparently no business of their own. Their voices, perspectives, and visions still wait to be heard and considered in their own development and that of their nation states (Lo-oh, 2009). They are most often understood from the perspective of the adult group or the old. In most parts of the world, they are conspicuous and vocal but always and almost an unheard cohort (Nsamenang, 2016). That is why they have often remained "silent others", the voiceless enfants terribles (Caputo 1995; Gottlieb 2000) and the incompetent category, blinded, confused and without a focused sense of vision. They are often constructed from the outside and from above as a "problem" or a "lost generation" (Cruise O'Brien, 1996) and living a life in "crisis" (Everatt and Sisulu, 1992). Most recently, they have been defined as a "black box", a "generation x" or the uncertain and doubtful "twenty somethings" with little or no idea where they are going (e.g. Arnett, 2000, 2004; Hening, 2010; 
Lo-oh, 2012). In line with this, however, the bulk of today's youth seems to exist in a world and culture of their own. There is a forceful youth culture which parents and other authority figures little understand (Nsamenang, 2016). This is typical in sub-Sahara Africa where very little is yet to be known about young people and their developmental assets and strivings, even though they constitute more than 70\% of Africa's population (Erny, 1987) and remain the continent's greatest resource, investment and hope for its future (Lo-oh, 2012, 2014; 2017).

Despite their critical value for future well-being, many African countries still have minimal investments towards the healthy development of adolescents and emerging adults (Knowles \& Behrman, 2005). Many have little or no access to education, employment and livelihoods, healthcare and basic nutrition (Honwana \& Boeck, 2005); and over the past two decades, political conflict, armed violence, and the HIV/AIDS pandemic created a crisis of unprecedented proportions for younger generations of Africans (Lo-oh, 2014). According to du Plessis (2010), they experience high levels of poverty and unemployment, low levels of literacy, skills and education attainment, HIV/AIDS infections, vulnerability to committing crime due to high levels of poverty, societal alienation and substance abuse, high rates of teenage pregnancy, and lack of information. School-to-work transitions are also a farce, demonstrating an academic pipeline problem which has made many young people expensive social liabilities rather than economic and social assets (Cooper, 2011). Within this stressful environment, how do young people organize and make sense of their daily lives? How do they negotiate their private and public roles and envision their futures? How do they cope with the harsh and excruciating realities so that they remain stable, positive and eventually lead productive lives today and in future?

Focusing on African young people, emerging adults, we find that discourse on them has not transcended the rhetoric of "calamity" that visualizes, casts and intervenes the young as problematic cohorts in the tedium of global imperatives offered to humanity by western civilization (Nsamenang, 2007). This is too true and common in Africa where arguments and beliefs that young people nurture and hold have rarely been read or listened to, and when their voices are not silenced, then their talk is never unconstrained. Their voices reach a broader platform only in rare, and sometimes tragic cases, but even then these sorry voices are often immediately recuperated, transformed, and inserted into different narratives and agendas set by other interest groups. For example, it is a visible reality in Africa to have politicians and those in authority depend on the youth not only for their votes, but in nearly all African countries where there have been risks of post-election rioting, they have always invited the youth to stand up and defend their votes, their voices and choices for their nation. Regrettably, once such politicians take office, they hardly ever go back to the youth, who are assumed incapable and without experience. In most cases, thereafter, the young are perceived through opposition to the old and as "people in the process of becoming rather than being" (Honwana \& Boeck, 2005; Nsamenang, 2007).

Besides the personality and identity crises aforementioned, the situation of young people in Africa is precarious as their vision for adulthood is ill-fated by difficult economic, social, political, cultural, health and psychological conditions which have left most of them hopeless of the future of their adulthood (Lo-oh, 2017, 2012). Health care services, economic resources, and social services are unevenly distributed across the continent such that a majority of Africa's emerging adults are left languishing in abject poverty, unemployment, under-sholarisation, and a difficult labour market economy (Lo-oh, 2012, 2009). With this it is increasingly difficult to manage the economics of adulthood including the challenges of becoming autonomous, financially independent, personally and socially responsible, emotionally stable and self-reliant (Lo-oh, 2017). As a result, several changes have occurred in youth life courses and as a result, education has extended into the late twenties and early thirties, family formation has been postponed, and many young people plan on remaining single and childless well into their thirties, if not indefinitely (Casper \& Bianchi, 2002). The transition to adult status has been transformed from a relatively clear-cut, linear pathway to a complex, non-linear, fragmented and individualized process dependent on the ability of each individual to navigate his or her way through a set of landmark events (Lo-oh, 2012).

Difficulties in understanding developmental trajectories for African young people and especially their experiences during emerging adulthood are compounded by absence or scarcity of specific studies on African young people, where there has been little or no discourse on growing up African. This is understandably so as developmental psychology, or better-still, research on emerging adulthood is branded a "Eurocentric enterprise" whose efforts have failed to capture the reality of growing up African (Lo-oh, 2009; Nsamenang, 2002), and in African contexts. Developmental psychologists, for example, those who focus on emerging adulthood have demonstrated visible and remarkable ethnocentrism, and have claimed that emerging adulthood is essentially a Euro-American and "industrialized countries"” enterprise (e.g. Arnett, 2000, 2004, etc). Their findings have also largely heralded young people in industrialized economies, segregating those in developing and emerging countries, as if to say that they do not go through the experiences of emerging adulthood. Understandably emerging adulthood for African young people like for African American youth constitutes a fraught passage (Arnett \& Brody, 2008) characterized by very complicated and difficult identity and society-based issues.

As many emerging adults have still not been able to answer the identity puzzle: Who Am I? and with personalities marked by identity explorations (Arnett, 2000; Lo-oh, 2017), they are prone to flounder and not 
flourish. But it is during this period of transition to adulthood that they must confront these issues, making enduring choices and embracing more rewarding future life trajectories. They must also shun the negative beliefs of their time and take their destiny in their own hands thereby ushering a new way of looking at their development-positive development-with emphasis on psychological capital, strengths or developmental assets they must tap from to re-orient their lives. This would require that they nurture an intentional process that promotes positive outcomes in their lives by individually and positively accessing opportunities, choices, relationships, and the support mechanisms necessary for their full participation in family and society. The promotion of agentic and resilient behaviour and the fostering of self-determination, self-efficacy, pro-social norms, clear and positive identity and belief in the future take central stage in the positive development of young people (Feierstein, 2011). In this conception, young people are therefore self-organizing, proactive, selfregulating and self-reflecting. They are creators and contributors to their life circumstances and not just products of them. To be agentic or resilient is to be able to intentionally influence one's functioning and life circumstances (Lo-oh, 2013), thereby shaping and re-shaping one's destiny, taking it into one's hands and being determined to move forward to a future that is not only perceived but desired.

\section{Emerging adulthood as a developmental stage}

The threshold between adolescence and adulthood, usually in the third decade of life, fondly referred to as the "twenty somethings" constitute what has been referred to in 20 years of research on young people as emerging adulthood (e.g. Arnett, 1998, 2000, 2004). Young adults who have graduated from high school and either entered university, the workforce or family life are the ones living through this period. On the one hand, they have the freedom to shape their future lives; and on the other hand, especially in most African societies, they are usually not fully independent of their parents, most often because they may lack stable social and economic status. That is why Arnett (1998) maintains that they are neither adults nor adolescents. They are still reflecting and experimenting with goals, values, skills, and beliefs in order to develop a true sense of self to ferry them to full adult status. Their psychological sense of self-judgment, decision making, self-assurance, self-competence, personal effort, personal agency, self-control, autonomy, independence, self-acceptance, and self-worthiness, are not well developed yet, but are on course and in progress. According to Hening (2010), decisions and actions during this time have lasting ramifications especially as the 20s (and up to the 30s) are when most young people accumulate almost all of their formal education; meet their future spouses and the friends they will keep; and start with the careers that they will stay with for many years to come. Again, this is when adventures and experiments of all kinds, travels, and relationships are embarked on. Emerging adulthood therefore, represents the years during which the most significant events of life are most likely to occur (Tanner, 2006). For example, many emerging adults will or would have graduated or finished school, moved out of parental residential home, found a full time paying job, rounded up a dating experience with marriage and begun parenthood. In most African cultures, they are even expected to construct and own a residential space of theirs even before marriage. But because of the challenges of becoming adult in today's society, Arnett $(2000,2004)$ maintains that this period is characterized by identity explorations, self-focus, possibilities, feeling in-between, and instability; characteristics that have often pulled the period too long for most African youth, sometimes into the fourth decade of life. The period also constitutes the challenge of "learning to stand alone," "self-sufficiency" and independence, all important markers of positive development for emerging adults. Based on these defining characteristics, the global percentage of youth in their twenties and thirties who would qualify as adult has decreased significantly in recent decades (Mortimer \& Aronson 2001). For example, today, many young people leave school as late as the late twenties and early thirties (and in some cases even up to the forties), marriage is largely postponed to the thirties and even more, and a single and childless life is highly solicited. These social changes have prompted new views of what constitutes adulthood or markers of adulthood. Among these views are "emerging adulthood" (Arnett, 2004, 2000), which now constitutes a phase of the life course extending between adolescence and adulthood; similarly, "youthhood" (Cote, 2000), "adolescenthood" (Nsamenang, 2005, 2002), "contestable adulthood" (Horowitz \& Bromnick, 2007), the "transition to adulthood" (e.g. Shanahan \& Longest, 2007), or the "twenty-somethings" (Hening, 2010) in which full adulthood is hopefully attained through personal strivings and effort (Shanahan \& Longest, 2007).

Emerging adults, unlike full adults, are undergoing a period of exploration where they can test out a series of possible life courses in love, work, and worldviews because they have not yet entered the enduring responsibilities that are normative in adulthood (Arnett, 2000; Barry \& Nelson, 2005). It is because young adults are in this period of exploration that their subjective sense of adulthood is based less on traditional sociodemographic markers but more on psychological markers (Settersten, 2006; Arnett, 2000; Shanahan, Porfeli \& Motimer, 2005). For these reasons, the transition to adulthood is characterised by heightened risk-taking behaviour and self-exploration of numerous domains (Arnett, 2000) which empty in the acquisition of the skills and attitudes needed to perform adult roles in positive and productive ways. It is largely a period when late adolescents and early adults begin to figure out what they want to do with their lives and how they might go 
about it. It presupposes that a developing individual acquires a set of characteristics that enables him or her to perform expected adult behaviours.

\section{Overcoming adversity and flourishing in emerging adulthood}

Studies on young people, especially adolescents have been framed and analyzed only in relation to their potentially disruptive behaviours (Lo-oh, 2014), stereotyped as abnormal and deviant (Santrock, 2005), "silent others" and voiceless enfants terribles (Caputo 1995; Gottlieb 2000; Hirschfeld, 2002), an incompetent category, blinded, confused and without a focused sense of vision (Gottlieb 2000). Freud had earlier described them as sexually driven and conflicted. Most recently, they are being defined as an "an in-between generation," a "black box", a "generation x" or uncertain and doubtful "twenty somethings" (e.g. Arnett, 2000, 2004; Nsamenang, 2016). These moorings coincide with international advocacies and global mindsets which value young people as dependents (Munday, 1979), without sufficient sense of initiative and maturity to act in their own self-interest and to exercise their right to self expression. Finally, widespread studies on adolescence have concluded that young people of every generation have appeared radical, unnerving, and different from adults in how they look, how they behave, and the kinds of things they enjoy (Santrock, 2005). African young people, growing up in deprived, troubled and threatening environments (Lee, Cheung \& Kwong, 2012) maintain positive adaptations (Rutter, 1987) and gear towards positive and beneficial outcomes in their futures despite the distressing life and demanding societal conditions.

Therefore, thinking of adolescence and emerging adulthood as a time of rebellion, crisis, pathology and deviation does little good and can do considerable disservice to young people. It is far more accurate to view adolescence and emerging adulthood as a time of evaluation, a time of decision making, and a time of commitment as young people carve out their place in the world (Santrock, 1993). It is apparently an enormous error to confuse the young person's enthusiasm for trying on new identities to mean outrageous behaviour and hostility towards parents and society. Searching for an identity is a time-honoured way in which young people move towards accepting, rather than rejecting parental and societal values.

Marked by social entrée and probation and "socialised" internship, it is a time when young people recognize and adjust to changes, perform domestic chores, participate in rights of passage to adulthood; visualize self, complete training and are poised for adult roles as they become junior partners as proto-adults (Nsamenang, 2016).

Despite the hardships young people face, many grow up to be capable, competent and productive adults. The concept of resilient youth too, often a reality among African emerging adults highlights competence and adaptability. Some research has found that resilient young people have one or more advantages that help them to overcome their disadvantages (Masten, 2001).

Unfortunately, many young people living in at-risk circumstances, characterised by such factors as poverty, lack of quality parenting, inadequate schools and high-crime neighbourhoods-are not resilient. There are a lot of young people at risk in African rural and urban centres: Almost $70 \%$ of all children and youth and nearly all rural children and youth in sub Saharan Africa live in poverty today (United Nations Population Fund, 2012). How competent they will eventually become often depends on their access to legitimate opportunities for growth, such as a quality education, community and societal support for achievement and involvement, and access to good and decent jobs (Santrock, 2005). Especially important in adolescents' development is long-term support from adults (and in some cases from peers) who deeply care about them (Hamilton \& Hamilton, 2009). There are success stories of Africans who have made it in life thanks to dedicated support from their peers who stretched out a helping hand from their advantaged position. In a study of social support in the future orientation of emerging adults in Cameroon, young people reported the need for partnerships, networks and lasting social support systems as resources that could positively accompany them to productive futures (Lo-oh, 2016). In particular, they pointed to family support, supportive peer relations, community support programmes like scholarships for continuing education, opportunities for professional training and employment and national agencies for productive youth development. In line with these findings, Larson (2000) has also found that young people, especially emerging adults need more opportunities to develop the capacity for initiative, such that they become self-motivated and expending some conscious effort to reach challenging goals. Health and wellness education will help them develop both cognitive and socio-emotional skills, including self-control, stress management skills, and communication skills.

\section{From positive psychology to positive individual development}

As seen, the transition from adolescence to full adult status is a critical developmental period shaped by individual, familial, social, historical and contextual circumstances. Certainly, many young people around the world experience such severe stressful circumstances like war, earthquakes, or terrorist acts, and adversities such as poverty and family disruption which in most cases have negative effects on subsequent developmental pathways. It is also well established that children exposed to hostile, stressful, and aversive early family 
experiences are at elevated risk for the development of adjustment problems (du Plessis, 2010). Myriad experiential factors have been linked to children's behaviour problem development, including economically disadvantaged circumstances, homes characterized by high levels of inter-parental conflict and violence, and physically punitive parental discipline (Cummings, Davies, \& Campbell, 2000). Yet these social contexts in which children and youth develop are varied and complex, particularly among African emerging adults. For example, not all individuals become as heavily affected by stressors as expected and rather show competence, thriving, and other positive outcomes instead of malfunction and problem behaviours (Weichold \& Sharma, 2011). Many African young people in spite of these deplorable conditions have continue to thrive and flourish. So even though Africa's youth are most prone to flounder as a result of their troubled circumstances, majority actually flourish and become very dependable, functional and productive in their futures. As such the topic of positive development is relevant in the African context; and provides a rare opportunity for an African voice/experience in the flourishing and floundering dichotomy in emerging adulthood.

Positive psychology is the scientific study of what makes life most worth living. It is the scientific study of positive human functioning and flourishing on multiple levels that include the biological, personal, relational, institutional, cultural, and global dimensions of life (Seligman \& Csikszentmihalyi, 2000). It is a call for psychological science and practice to be as concerned with strength as with weakness; as interested in building the best things in life as in repairing the worst; and as concerned with making the lives of normal people fulfilling as with healing pathology (Peterson, 2009).This application suggests the flourishing/floundering dichotomy such that the goal of positive psychology is going beyond barriers to source hidden or unidentified opportunities. In relation to human/youth development, positive psychology lays emphasis on healthy development or "the good life" referring to the greatest value in life-the factors that contribute the most to a welllived and fulfilling life (Seligman, 2009). This article takes a look at positive healthy development in emerging adulthood in Africa. As such we focus on flourishing with a hypothetical contention that African youth in their twenties, albeit the deplorable realities of their existence and time, still lead positive, healthy and productive lives; and even as they are prone to floundering circumstances, they achieve optimal human functioning and flourish in their adulthood.

Flourishing, in positive psychology, refers to optimal human functioning. It comprises four elements: goodness, generativity, growth, and resilience (Fredrickson, 2005). According to Fredrickson (2005), goodness is made up of: happiness, contentment, and effective performance; generativity is about making life better for future generations, and is defined by broadened thought-action repertoires and behavioural flexibility; growth involves the use of personal and social assets; while resilience reflects survival and growth after enduring a hardship. A flourishing life stems from mastering all four of these elements. Therefore, a flourishing life connotes well-being and satisfaction (past), flow, joy, the sensual pleasures, and happiness (present) as well as constructive cognitions about the future, including optimism, hope, and faith (Gillham \& Seligman, 1999). At an individual level, positive development is about positive individual traits with emphasis on the capacity for love and vocation, courage, interpersonal skills, aesthetic sensibility, perseverance, forgiveness, originality, futuremindedness, high talent, and wisdom; and at group level positive development is about civic virtues and the institutions that move individuals toward better citizenship such as responsibility, nurturance, altruism, civility, moderation, tolerance, and work ethic (Seligman \& Csikszentmihalyi, 2000; Seligman, 2009; Gilham \& Seligman, 1999).

Positive psychologists are concerned with a life of positive experiences, enduring psychological traits, positive relationships and positive institutions; and emphasize states of pleasure or flow, values, strengths, virtues, talents, as well as the ways that these can be promoted by social systems and institutions (Peterson, 2009). Four typologies of mental health functioning often considered include flourishing, struggling, floundering and languishing (Keyes \& Lopez, 2002). That is why developmental scientists have suggested that positive youth development encompasses psychological, behavioral, and social characteristics that reflect what they call the "Five Cs" (Eccles \& Gootman, 2002). These "Cs" constitute competence, confidence, connection, character, and caring/compassion. An individual that develops in any of these is said to be thriving or flourishing. In addition, a thriving or flourishing individual also further develops a sixth " $C$ " which represents "contribution" either to self, family, community, or civil society (Zarrett \& Lerner, 2008)

Theoretical approaches to positive development include prevention science, positive psychology, applied developmental science, competence enhancement, health promotion, resilience, wellness, and positive youth development (Seligman \& Csikszentmihalyi, 2000). It also includes the zeal for positive outcomes. Striving for positive outcomes allows us to open our eyes and look at young people holistically and strengths-based. Who are they? What skills, interests, and talents do they bring to the table? Identifying and building on their strengths will engage and motivate them to learn and experience more. In specific terms, positive development presupposes that young people have as much choice and as much control as possible over the activities in which they engage (Hamilton \& Hamilton, 2009). Variously termed participation, voice, and empowerment, this principle is based both on fundamental democratic values and on a view of human beings as active agents and shapers of their own 
development. As such young people especially emerging adults should have a say both as a right and as an essential part of the positive developmental experience. A fundamental orientation has focused on developmental and psychological assets that young people incarnate which ought to be explored and harnessed to support positive healthy individual development.

Developmental assets are specific constructs which predict future success, including positive individual characteristics and environmental resources (Scales \& Leffert, 2004). The developmental assets model includes internal and external assets, including positive characteristics of the individual as well as positive influences present in the individual's environment, respectively (Leffert, Benson, Scales, Sharma, Drake \& Blyth, 1998). According to them, internal assets are characteristics such as commitment to learning, future planning, and a sense of positive identity while external assets include variables such as availability of support systems, opportunities for empowerment, and structure for the constructive use of time. The model has been found to be an empirically supported predictor of factors such as: high-risk behavior, thriving outcomes, and resiliency. These assets are also seen as "building blocks," because when they are present it is suggested that adolescent lives are enhanced in multiple ways (i.e., physically, academically, socially) and do establish a solid foundation for positive development (Benson, 1997).

As earlier mentioned, the developmental assets model emphasizes both internal and external assets (Benson, 1997). Internally, assets regarding intrinsic motivation to achieve knowledge and success are grouped as "commitment to learning," while assets of personal character that guide judgment constitutes the "positive values" category. Assets pertaining to social maturity make up the "social competencies" category, while those having to do with self-efficacy and self-esteem constitute the "positive identity" category (Scales \& Leffert, 2004). In other words, intrinsically motivated school-going emerging adults are committed to their school related tasks, desire to achieve knowledge and school success; and above all committed to their learning. For some, they build a set of values, especially positive values on which they depend to make sound judgments as they enter full adulthood. And as they move through social entrée, and probation and "socialised" internship, a key task is that of building social competence and a positive identity that will help them fully integrate into and become full members of their adult society. Externally, assets concerning the presence of love and acceptance are accounted for under the "support" category. Those regarding the ability to feel safe and valued are under the "empowerment" category. Assets related to the presence of appropriate rules, guidelines, and anticipations set in place by institutions (family, school, work) constitute the "boundaries and expectations" category. Finally, the presence and availability of activities that may stimulate positive growth are part of the "constructive use of time" category (Scales \& Leffert, 2004). These categories suggest the importance of social support systems and benefits of environmental resources in order to thrive in difficult circumstances. In fact, positive psychology emphasizes that all youth are capable of thriving if they are supported by contexts that provide opportunities for developing their unique strengths and competencies.

The developmental assets model also assesses a wide array of outcome factors categorized as either thriving or risk behaviours. This orientation posits that individuals who possess a higher number of developmental assets are more likely to exhibit success, or thriving behavior, in the future. Thriving is defined by one's overall success in school, commitment to helping others, valuing diversity, maintaining good physical health, delaying gratification, and overcoming adversity. These thriving indicators allow researchers to investigate the predictive strength of developmental assets and provide insight for interventions which help young people succeed (Benson, 1997). Conversely, the model suggests that individuals with fewer assets may be more likely to engage in risk behaviour, such as drug and tobacco use, multiple sexual encounters, legal trouble, physical altercations, and skipping school. They may also experience developmental delays in some measures of adulthood, either in school completion, employment, exit from parental residence, dating and marriage, and child birth and parenthood.

\section{Resilience and agency as platforms for positive development}

Emerging adulthood resilience research differs from risk research as it focuses on the assets and resources that enable some young people to overcome the negative effects of risk exposure. Resilience has been variously defined as positive developmental outcomes in the face of adversity or stress (Masten, 2001); being relatively resistant to psychosocial risk experiences (Rutter, 1999); successful adaptation or the development of competence despite high-risk status or chronic stress (Egeland, Carlson \& Sroufe, 1993); and the capacity of dynamic systems to withstand or recover from significant disturbances (Masten, 2007). Simply put, it is the process of overcoming the negative effects of risk exposure, coping successfully with traumatic experiences, and avoiding the negative trajectories associated with risks. While differing in terminology, such definitions describe the two common factors necessary for defining resilience: firstly the experience of adversity or stress, and secondly, the achievement of positive outcomes with the help of promotive factors that either help bring about a positive outcome or reduce or avoid a negative outcome (Masten, 2007). And promotive factors for positive outcomes are highly solicited in efforts towards positive youth development, especially in developing countries. 
Key to these promotive factors are resilient behaviour and personal agency.

Early research identified resilience as a characteristic of the individual (Anthony \& Cohler, 1987), and considered resilient children and youth to be exceptional individuals who are unique in their ability to prevail against the odds. Current research now predominantly views resilience as the process by which individuals draw on personal characteristics (psychological capital) and resources in their environment to enable them successfully negotiate adversity (Luthar \& Zigler, 1991). As such, resilience is not seen as a static characteristic of an individual, but rather a dynamic process across contexts and throughout the life span. The process of resilience can be seen as arising from interactions which are central to normal developmental processes that commonly occur and may even be seen as ordinary (Masten, 2001).

Although very often exposed to adversities of all kinds: individual, familial, institutional, and contextual, African young people often flourish significantly to become productive individuals in adulthood as well as responsible citizens of their community and country. Whether for themselves as individuals, in the family or community context, young people grow up challenged to make a difference, to become better than their parents did, and to "make a name" for themselves, their family or their community (Lo-oh, 2017). Developmental trajectories as well as child-rearing practices challenge them to harness and use personal assets which predispose them to positive developmental pathways. Such common assets among African youth are resilience, agency, psychological capital, personhood, social support networks, life skills, skill and competence building, ecocultural context, asset building, youth engagement, as well as risk prevention in communities and families (Nsamenang, 2002; Lee, Cheung \& Kwong, 2012; Schwartz, Côte \& Arnett, 2005). Resilience explains why African children and youth, though growing up in deprived, troubled and threatening environments as well as distressing and demanding life conditions (Lee, Cheung \&Kwong, 2012) still maintain positive adaptations (Rutter, 1987) and gear towards positive and beneficial outcomes in their futures.

In the face of adversity, emerging adults in sub-Sahara Africa often in a healthy manner, renegotiate such difficult experiences and bounce back. A study of family poverty among the Bakweri of Cameroon (Tchombe, Shumba, Lo-oh, Gakuba, Zinkeng\&Teku, 2012) found that among other strategies, resilience stood out as a major framework for navigating poverty. Among common resilient behaviours were personal strengths, neighbourhood resources, positive attitude to life, social skills building, social responsiveness and sensitivity, positive peer interactions, empathy, social support systems and solidarity as well as strong family support ties. South African studies have maintained that protective resilient coping strategies among emerging adults are anchored in the individual self, family, community as well as culture (Theron \& Theron, 2010; Leoschut \& Burton, 2009; Kruger \& Prinsloo, 2008; Theron, 2004). They identified personality traits such as goal or achievement orientation, empathy, optimism, independence and autonomy, conscientiousness and self-regulation, extroversion and enthusiasm as well as assertiveness as self-related protective resources.

On its part, personal agency refers to one's capability to originate and direct actions for given purposes. It is influenced by the belief in one's effectiveness in performing specific tasks, which is termed self-efficacy, as well as by one's actual skill. The onset of adolescence marks a profound shift in expectations regarding young people's ability to assume responsibility for their functioning. Adolescents with a strong sense of efficacy for their development are more agentic, resilient and better able to resist the adverse influences in their development (Bandura, 2005). To overcome adversity, adolescents develop diverse self-regulatory skills, such as goal setting, self-monitoring, time management, and self-evaluation. Self efficacy refers to subjective judgments of one's capabilities to organize and execute courses of action to attain designated goals (Bandura, 2005). And among the mechanisms of human agency, none is more central or pervasive than beliefs of personal efficacy. This core belief is the foundation of human motivation, well-being, and accomplishments. Unless people believe they can produce desired effects by their actions, they have little incentive to act or to persevere in the face of difficulties (Bandura, 2005). Whichever other factors serve as guides and motivators, they are deeply rooted in the core belief that one has the power to effect change or changes by one's actions. It means that emerging adults are creators of their worlds, be they success stories or failure in life. And so it becomes imperative for emerging adults to be empowered to take their lives and destinies into their own hands, irrespective of challenges that may prone them to floundering. The lesson is that they ought to learn from others and take their overbearing challenges as "stepping stones" from where to build positive healthy futures for themselves.

\section{Conclusion}

This article has argued that emerging adults who are exposed to hostile, stressful, and aversive experiences are at elevated risk of floundering such that they do not flourish in adulthood. Myriad experiential factors have equally been linked to young people's behaviour problem development, including economically disadvantaged circumstances, homes characterized by high levels of parental conflict and violence, and physically punitive parental discipline (McLoyd, 1998). Observations in urban centres across Africa depict that young people are getting less well behaved and more anti-social than they have ever been at any one period in history. And while Twenge (2006) referred to emerging adults as "Generation Me" typified as narcissistic, self-absorbed and 
unhappy, Smith (2011) referred to them as generally lost in transition, a condition reflected in their moral confusion, risk behaviours, materialism, and disengagement. Aside these, social and economic inequalities in the African continent also contribute a significant share of the challenges standing on the road to adulthood for young Africans. For example, wealthier adolescents and those in urban areas are more likely to be in school than their poor rural counterparts, and thus enjoy significant advantages in a labour market that increasingly rewards credentials. Economic resources and social services are unevenly distributed and majority of youth are languishing in abject poverty, unemployment, under-sholarisation, and a difficult labour market economy.

Of course, exposure to these myriad of adversities does not fore-ordain adjustment and future life difficulties. Despite the popularization of the literature on the negative or dark side of adolescence and emerging adulthood, there is also mounting evidence that this time period, at least for a significant majority, is a unique developmental period in which positive development is fostered (Nelson \& Padilla-Walker, 2013; PadillaWalker, 2015). Increasingly in the literature, the deficit model is being replaced by strength models-positive youth development model. The deficit model is also being replaced by a growing interest in resilient young people-those expected to do poorly, based on risk factors (e.g., poverty), but who beat the odds and do well-and, conversely, those who are expected to do well, based on a lack of risk factors (e.g., affluent children), but who do not (Lo-oh, 2017). Many African children and youth raised in very difficult family and societal circumstances show good adjustment later in life, and tend to proceed and develop more positively than expected. They are more likely to flourish than flounder. Like in the literature, those who have a sense of competence, confidence, connection to people and institutions, character and caring for others will in turn contribute to their families, communities and societies (Lerner, Lerner, von Eye, Bowers \& Lewin-Bizan, 2011).

How flourishing triumphs over floundering has been a question for strength-based models of child and youth "resilience" and the search for countervailing experiences that might offset early experiential risks (Luthar, Cicchetti, \& Becker, 2000). Flourishing leads to and is evidenced by both the promotion of positive behaviours and the avoidance of negative ones (Padilla-Walker \& Nelson, 2017). Yet other psychologists have discussed how unrealistic, obsessive, or reckless positive thinking impedes productive action, causes delusional assessments of situations, and that people are then blamed for not visualizing hard enough, as such, attracting failure (Held, 2004). But this may just be a one sided perspective since individual dimensions of flourishing may differ across emotional, psychological and social well-being. Emotionally, flourishing is viewed as experiencing feelings of happiness, optimism or general positive affect (North, Holahan, Carlson \& Phal, 2014; Diener, Tov, Kim-Prieto, Oishi \& Biswas-Diener, 2010) cited in Padilla-Walker \& Nelson (2017). It is also viewed as psychological well-being, the ability to cope and for optimal mental health (Keyes, 2002). And when in social situations, flourishing is seen through successful functioning, such as in comfort in relationship contexts, taking on leadership roles, helping others and valuing diversity (Scales, Benson, Leffert \& Blyth, 2000). They also add a number of behaviours or attributes that can indicate flourishing such as displaying self-control, avoiding procrastination, seeking educational attainment and maintaining one's physical health.

As a theoretical framework, positive development provides a refreshing perspective on the social and emotional development of emerging adults. Rather than focusing on the risks associated with development, positive psychology promotes the study of what is going right, emphasizing personal assets and positive engagement (Larson, 2000). As shown, positive development may also include pro-social behaviour, belief in the future, and spirituality. This perspective stands in contrast to traditional notions of success. An adolescent may be a good student and stay out of trouble, but may lack the skills needed to thrive as an adult and become an active citizen. Positive psychology emphasizes that all young people are capable of thriving if they are supported by contexts that provide opportunities for developing their unique skills and strengths. Examples have also been shown of those in less supportive environments but who have rather used their challenging situations as "stepping stones" on which to bounce back to create "magic-type" success stories. Whether in the family or community context, young people grow up challenged to make a difference, to do better than their parents did and to "make a name" for themselves, their family and community (Lo-oh, 2017).

In line with these, research on resilience has been a major theme in developmental psychopathology focusing on the question of why some children and adolescents maintain positive adaptation despite experiences of distressing life conditions and demanding societal circumstances such as violence, poverty, stress, trauma, deprivation, and oppression. We have therefore discussed resilience and agency as the processes of effectively mobilizing internal and external resources in adapting to or managing significant sources of stress or trauma during development. As such, cultivating agentic and resilient behaviours means fostering young people's capacity, flexibility, and coping strategies as they face developmental changes and life stressors in order to "bounce back" from difficult life experiences and achieve positive outcomes in life. Our hope therefore is that of greater measures to support positive development for emerging adults in Africa so that albeit all odds, adversities and trauma, affecting their hopes and aspirations, they can flourish and not flounder in their futures. 


\section{References}

Anthony, E.J. \& Cohler, B.J. (1987). The invulnerable child. New York: The Guilford Press.

Araia, B.B. (2007). Eritrea. In Jeffrey Jensen Arnett (Ed.) (2007). International encyclopedia of adolescence. New York: Routledge.

Arnett, J. J. (2004). Emerging adulthood: The winding road from the late teens through the twenties. New York: Oxford University Press.

Arnett, J.J. (2000). Emerging adulthood: A theory of development from the late teens through the twenties. American Psychologist, 55, 469-480.

Arnett, J.J. (2000). High hopes in a grim world: Emerging adults' views of their futures and Generation X. Youth \& Society, 31(3), 267-286.

Arnett, J.J. (1998). Learning to stand alone: the contemporary American transition to adulthood in cultural and historical context. Human Development (41) 295-315.

Arnett, J.J. \& Brody, G.H. (2008). A fraught passage: The identity challenges of African American emerging adults. Human Development 2008;51:291-293

Bandura, A. (2005). Adolescent development from an agentic perspective. Self-Efficacy Beliefs of Adolescents, $1-43$

Barry, C.M. \& Nelson, L.J., (2005). The role of religion in the transition to adulthood for young emerging adults. Journal of Youth and Adolescence, 34.

Bauman, Z. (2001). The individualized society. Cambridge, UK: Polity.

Benson, P.L. (1997). All kids are our kids: What communities must do to raise caring and responsible children and adolescents. San Francisco: Jossay-Bass

Casper, L.M. \& Bianchi, S.M., (2002). Continuity and change in the American family. Thousand Oaks, CA: Sage Publications.

Caputo, V. (1995). Anthropology's silent 'others': A consideration of some conceptual and methodological issues for the study of youth and children's cultures. In V. Amit-Talai and H. Wulff (1995) Youth Cultures: A Cross-cultural Perspective. London: Routledge.

Copper, C.R. (2011). Bridging multiple worlds: Cultures, identities, and pathways to college. Oxford: Oxford University Press.

Côté, J.E. (2000). Arrested adulthood: The changing nature of maturity and identity. New York: New York University Press.

Dusek, J.B. (1991). Adolescent development and behaviour. New Jersey: Prentice Hall.

Eccles, J.S. \& Gootman, J.A. (2002). Community programs to promote youth development. Washington, DC: National Academy Press.

Egeland, B., Carlson, E. \& Sroufe, L.A. (1993). Resilience as process. Development and Psychopathology, 5(4), 517-528.

Erny, P. (1987). L'enfant et son milieu en Afrique noire (The child and his environment in black Africa). Paris: L'Harmattan.

Furlong, A., \& Cartmel, F. (1997). Young people and social change: Individualization and risk in late modernity. Buckingham, UK: Open University Press.

Gillham, J.E., \& Seligman, M.E.P. (1999). Footsteps on the road to positive psychology. Behaviour Research and Therapy, 37, 163-S173.

Gottlieb, A. (2000). Where Have All the Babies Gone? Toward an Anthropology of Infants and Their Caretakers. Anthropological Quarterly 73 (3): 121-32.

Hagan, J., \& Foster, H. (2003). S/he's a rebel: Toward a sequential stress theory of delinquency

and gendered pathways to disadvantage in emerging adulthood. Social Forces, 82, 53-86.

Hamilton, S.F. \& Hamilton, M.A., (2009). The transition to adulthood: Challenges of poverty and structural lag. In R.M. Lerner \& L. Steinberg (Eds.), Handbook of adolescent psychology, Volume 2: Contextual influences on adolescent development ( $3^{\text {rd }}$ ed.), 492-526. Hoboken, NJ: John Wiley \& Sons.

Held, B. S. (2004). The negative side of positive psychology. Journal of Humanistic Psychology 44 (1): 9-41.

Hening, R.M. (2010). What is it about 20 somethings? Downloaded on August 222010 from: http://www.nytimes.com/2010/08/22/magazine/22Adulthood-t.html?pagewanted=10\&_r=2

Horowitz, A.D. \& Bromnick, R.D., (2007). Contestable adulthood: variability and disparity in markers for negotiating the transition to adulthood. Youth \& Society, 209-231, Downloaded from http://yas.sagepub.com at University of British Columbia on June 6, 2009.

Keyes, C.L.M. (2000). The mental health continuum: From languishing to flourishing in life. Journal of Health and Social Behaviour, 43(2), 207-222.

Keyes, C.L.M., \& Lopez, S.J. (2002). Toward a science of mental health: Positive directions in diagnosis and interventions. In C.R. Snyder \& S.J. Lopez (Eds.), Handbook of positive psychology (pp. 45-59). London: Oxford University Press. 
Kruger, L. \& Prinsloo, H. (2008). The appraisal and enhancement of resilience modalities in middle adolescents within the school context. S Afr J Educ, 28(2), 241-259.

Lee, T.Y., Cheung, C.K. \& Kwong, W.M. (2012). Resilience as a positive youth development construct: A conceptual review. The Scientific World Journal, Vol 2012, http://dx.doi.org/10.1100/2012/390450

Leffert, N., Benson, P.L., Scales, P.C., Sharma, A.R., Drake, D.R., \& Blyth, D.A. (1998). Developmental assets: Measurement and prediction of risk behaviour among adolescents. Applied Developmental Science, 2(4), 209-230.

Lerner, R.M., Lerner, J.V., von Eye, A., Bowers, E.P. \& Lewin-Bizan, S. (2011). Individual and contextual bases of thriving in adolescence. A review of the issues. Journal of Adolescence, 34, 1107-1114.

Lo-oh, J.L. (2017). Positive development in Africa. In Padilla-Walker, L.M. \& Nelson, L.J. (eds.), Flourishing in emerging adulthood: Positive development during the third decade of life. Oxford: Oxford University Press.

Lo-oh, J.L. (2016). The role of social support in the future orientation of emerging adults in Cameroon. European Journal of Research in Social Sciences, 4(7), 43-54.

Lo-oh, J.L. (2014). "Le Cameroun des Grands Ambitions": The place for the youth in Cameroon's "Vision 2035" to become an emerging economy in 2035. Journal of Educational Policy and Entrepreneurial Research (JEPER), 1(4), 117-127.

Lo-oh, J.L. (2013). Children as agents of their own development and learning: a new paradigm shift in early childhood education. In Gwatirera Javangwe and Innocent Chirisa (Eds.), Navigating the contours of African childhood experiences: multidisciplinary perspectives. Bethesda : Academica Press

Lo-oh, J.L. (2012). Self-perceived adult status among emerging adults in the developing world: The Cameroon example. Hull Journal of Educational Advancement, 1(1), 1-9.

Lo-oh, J.L. (2009). Youth transitions to adulthood: Changes, trends and implications for preparing the next generation of Africa. CODESRIA, 3 \& 4, 33-42.

Luthar, S. \& Zigler, E. (1991). Vulnerability and competence: A review of research on resilience in childhood. American Journal of Orthopsychiatry, 61(1), 6-22.

Luthar, S.S., Cicchetti, D, Becker, B. (2000). The construct of resilience: A critical evaluation and guidelines for future work. Child Development, 71:543-562.

Masten, A. S. (2007). Resilience in developing systems: Progress and promise as the fourth wave rises. Development and Psychopathology, 3, 921.

Masten A.S. (2001). Ordinary magic: Resilience processes in development. American Psychologist, 56(3), $227-$ 238.

Mazrui, A.A. (1986). The Africans. New York: Praeger.

McLoyd, V.C. (1998). Socioeconomic disadvantage and child development. American Psychologist, 53:185-204.

Mortimer, J. T. \& Aronson, P., (2001). Adulthood. In E. Borgatta and R. J. V. Montgomery (Eds.). Encyclopedia of Sociology. New York: Macmillan.

Munday, E. (1979). Commentary. When is a child a 'child'? Alternative systems of classification. Journal of the Anthropological Society of Oxford, 10(3), 161-172.

Nelson, L.J. \& Padilla-Walker, L.M. (2013). Flourishing and floundering in emerging adult college students. Emerging Adulthood, 1(1), 67-78.

Nsamenang, A.B. (2007). African youth struggles into the local and global workforces. Paper presented at the Jacobs Foundation Conference on the "Transition from School to Work", Marbach Castle, April 12-14 2007.

Nsamenang, A.B. (2016). The Developmental psychology of human diversity. Bamenda: HDRC Publications.

Nsamenang, A.B. (2005). Educational development and knowledge flow: Local and global forces in human development in Africa. Higher Education Policy, 18, 275-288.

Nsamenang, A.B. (2002). Adolescence in sub-Saharan Africa: An image constructed from Africa's triple inheritance. In B.B. Brown, R. Larson, \& T.S. Saraswathi (Eds.), The world's youth: Adolescence in eight regions of the globe. London: Cambridge University Press.

Padilla-Walker, L.M. (2015). Moral development during emerging adulthood. In J.J. Arnett (Ed.), The Oxford handbook of emerging adulthood (pp. 449-463). New York, NY: Oxford University Press.

Peterson, C. (2009). Positive Psychology. Reclaiming Children and Youth, 18(2), 3-7.

Rutter, M. (1999). Resilience concepts and findings: Implications for family therapy. The Association for Family Therapy and Systemic Practice, 21, 119-144.

Rutter, M. (1987). Resilience in the face of adversity: Protective factors and resistance to psychiatric disorder. $\mathrm{Br}$ J Psychiatry, 147, 598-611.

Santrock, J.W. (2005). Life-span development. Madison: Brown \& Benchmark.

Santrock, J.W. (1993). Adolescence. Dubuque, IA: Brown \& Benchmark.

Scales, P.C. \& Leffert, N. (2004). Developmental assets: A synthesis of scientific research on adolescent development. Minneapolis, MN: Search Institute

Scales, P.C., Benson, P.L., Leffert, N. \& Blyth, D.A. (2000). Contribution of developmental assets to the 
prediction of thriving among adolescents. Applied Developmental Science, 4(1), 27-46.

Schwartz, S.J., Côté, J.E. \& Arnett, J.J., (2005). Identity and agency in emerging adulthood: two developmental routes in the individualization. Youth \& Society, 37(2), 201-229.

Smith, C. (2011). Lost in transition: The dark side of emerging adulthood. New York, NY: Oxford University Press.

Smith, B.W. (2002). Vulnerability and resilience as predictors of pain and affect in women with arthritis. Dissertation Abstracts International Part B, 63(3), article 1575.

Seligman, M.E.P. (2009). Authentic Happiness. New York: Free Press.

Seligman, M.E.P. \& Csikszentmihalyi, M. (2000). Positive psychology: An introduction. American Psychologist 55 (1): 5-14. doi:10.1037/0003-066X.55.1.5. PMID 11392865.

Serpell, R. (1994). An African social ontogeny: Review of A. Bame Nsamenang (1992). Human development in cultural context: A third world perspective. Cross-cultural Psychology Bulletin, 28 (1), 17-21.

Settersten, R.A. (2006). Becoming adult: Meanings and markers for young Americans. In P. Carr \& M. Kefalas (Eds.), Coming of age in America. Chicago: University of Chicago Press.

Shanahan, J.M., Porfeli, E. \& Motimer, J., (2005). Subjective age identity and the transition to adulthood: When does one become an adult? In R. Al, Jr. Settersten, F.F. Furstenberg, Jr., and R.G. Rumbaut (Eds.). On the frontier of adulthood: Theory, research and public policy. Chicago: University of Chicago Press.

Shanahan, J.M. \& Longest, K., (2007). Thinking about the transition to adulthood: From grand theories to useful theories. Keynote address at the Jacobs Foundation Conference on the "Transition from School to Work", Marbach Castle, April 12-14 2007

Shumba, A. \& Seeco, E.G., (2007). Botswana. In Jeffrey Jensen Arnett (Ed.) (2007). International encyclopedia of adolescence. New York: Routledge.

Tanner, J. (2006). Recentering during emerging adulthood: A critical turning point in life span human development. In J. Arnett \& J. Tanner (Eds), Emerging adults in America: Coming of age in the $21^{\text {st }}$ century (21-55). Washington, DC: American Psychological Association.

Tchombe, T.M. \& Lo-oh, J.L. (2012). Adolescents in Cameroon. In Jeffery Jensen Arnett (Ed.), Adolescent psychology around the world. Boston: Psychology Press.

Tchombe, T.M., Shumba, A., Lo-oh, J.L., Gakuba, T.O., Zinkeng, M.K. \& Teku, T.T. (2012). Psychological undertones of family poverty in rural communities in Cameroon: Resilience and coping strategies. South African Journal of Psychology.

Theron, L.C. (2004). The role of personal protective factors in anchoring psychological resilience in adolescents with learning disabilities. S Afr J Educ, 24(4), 317-321.

Theron, L.C. \& Theron, A.M.C. (2010). A critical review of studies of South African youth resilience, 19902008. South African Journal of Science, Article No. 252.

Twenge, J.M. (2006). Generation me: Why today's young Americans are more confident, assertive, entitled-and more miserable than ever before. New York, NY: Free Press.

Wallace, C., \& Kovatcheva, S. (1998). Youth in society: The construction and deconstruction of youth in East and West Europe. London: Macmillan.

White, N. R. (2003). Changing conceptions: Young people's views of partnering and parenting. Journal of Sociology, 39(2), 149-164.

Zarrett, N. \& Lerner, R.M. (2008). Ways to promote the positive development of children and youth. Brief Research-to-Results, 2008-11 